
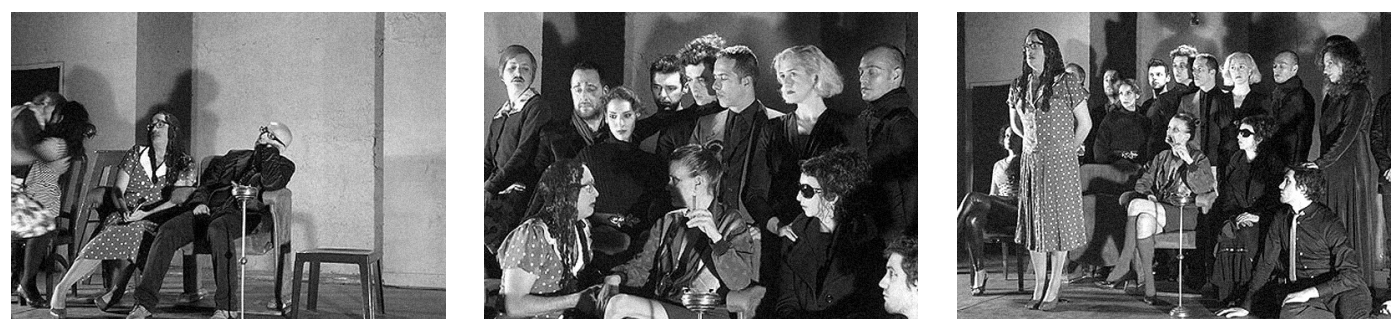

\title{
Das pequenas e iluminadas coisas
}

\author{
Ana Pais
}

Na folha de sala do espectáculo Juanita Castro podia lerse: "Juanita Castro é um espectáculo que poderia não ser feito. Não há nada a expressar através dele. É um caso sem importância". Foi este o manifesto de intenções com que Miguel Loureiro apresentou ao público o seu mais recente projecto, que acorreu, a rodos e em festa, à Casa Conveniente, entre 21 e 30 de Dezembro de 2008. 0 boato espalhara-se num ápice: aquele "caso sem importância", aquela pequena coisa ganhara inesperadas proporções de grande acontecimento, que ninguém queria perder.

Mas, como pôde isso acontecer assim, em apenas sete dias de discretas representações, divulgada por meios tradicionais (vulgo, pelo boca-a-boca), sem vintém para ensaios nem pagamentos (sem subsídios, portanto), sem actores que soubessem o texto, com mais figurantes do que actores, sem adereços, sem aquecimento, sem per diem, sem cenário e com um texto de teatro... ridículo? Obviamente, a resposta encontra-se não somente no fenómeno de adesão do público mas também, e sobretudo, na pertinência da proposta artística. E acontece, justamente, o júri discordar em absoluto do encenador em causa, decidindo atribuir a Juanita Castro uma Menção Especial, posto que o considera um caso de extraordinária importância para o panorama das artes performativas em Portugal: para todos os que o fizeram, os que o viram e os que o não viram.

Do jogo de forças entre os recursos mínimos de produção e as cumplicidades reunidas, surge um inesperado e refrescante prazer do fazer artístico, como uma descoberta de criança. Por esta deslumbrante e festiva alegria e pela capacidade de entabular um diálogo relevante com as várias heranças das artes de palco, Juanita Castro merece o maior reconhecimento deste júri, na pessoa do Miguel Loureiro. 0 encenador assume neste espectáculo uma posição artística de uma inteligência notável e despretensiosa: ele coloca-se no lugar do pequeno, do que se oferece ao olhar (e ao riso) do outro: "o grande", ou seja, o espectador. Trata-se, portanto, de um lugar risivel, de acções insignificantes e caracteres inferiores, porém, não de um gesto irrelevante ou dispensável. Por um lado, a partir da simplicidade que a caracteriza, a pequena coisa expande-se no entusiasmo partilhado de uma exuberante e disparatada viagem, não só orientada por um sentido apurado da justeza e do detalhe mas também sedimentada num profundo conhecimento das formas teatrais e da performance. Por outro lado, embora o ridículo seja a medida do pequeno, o gesto de Miguel Loureiro não poderia nunca ser ridículo: consiste na coragem de se medir com a grandeza da história das artes performativas, ombreando sem arrogância nem pretensa genialidade com os grandes de épocas de sua eleição, posicionando-se nela como num pequeno lugar de grande saber.

À sua maneira inquietante e pulverizada, Miguel Loureiro é um criador que ensaia pensamentos na prática, um verdadeiro estudioso que partilha a sua reflexão em cintilantes apontamentos de palco. Conhecendo o seu vasto leque de interesses, não será de espantar que, no início de 2008, Miguel Loureiro se tenha lançado numa encenação de Os persas, de Ésquilo, e, pouco depois, na performance Strange Fruit; nem tampouco que a sua linha de trabalho sobre os clássicos remeta para anteriores espectáculos como o inaugural Pompeia (1999) e Um Édipo (2003), ou que a pesquisa sobre atmosferas cénicas, de um ponto de vista plástico e teatral, nos faça pensar em espectáculos desafiantes como A carta roubada (2007). Esta dispersão eclética tem sido, de resto, a marca de autor no seu meticuloso percurso pela Antiguidade, pela dramaturgia contemporânea e pela performance, cujo elo se encontra na sua admirável erudição e num questionamento persistente ao longo de 13 anos de carreira.

No caso, Miguel Loureiro regressa aos efervescentes anos 60 e ao suigeneris esplendor underground da Factory, em Nova lorque. Escrita por Ronald Tavel em 1965, The Life of Juanita Castro consiste num dos primeiros textos do "Teatro do Ridículo". Foi um filme, realizado por Andy Warhol, antes de ser uma peça de teatro, levada à cena no mesmo ano, pelo próprio Tavel (que representava a personagem do encenador), tendo sido um tal sucesso de público que, em 1967, seria reposta em cartaz. Trata-se de uma paródia à figura de Juanita Castro, irmã de Fidel Castro, participante activa da revolução cubana, todavia conhecida pela sua oposição ao regime, sob a forma de um retrato de família muito particular. Embora sendo um assunto candente na sociedade americana da época, a peça centra-se menos na crítica política da situação e mais no jogo teatral lúdico a partir de caricaturas e subversões das figuras da história. Ela sustenta-se num ambiente geral de provocação nonsense camp, sugerido pela opção de um elenco cross-gender, em que apenas duas personagens deveriam ser representadas por homens (o encenador e Juanita) e todas as outras por mulheres. De acordo com o autor, Juanita também não deveria ser
Ana Pais

é professora na Escola Superior de Teatro e Cinema. 

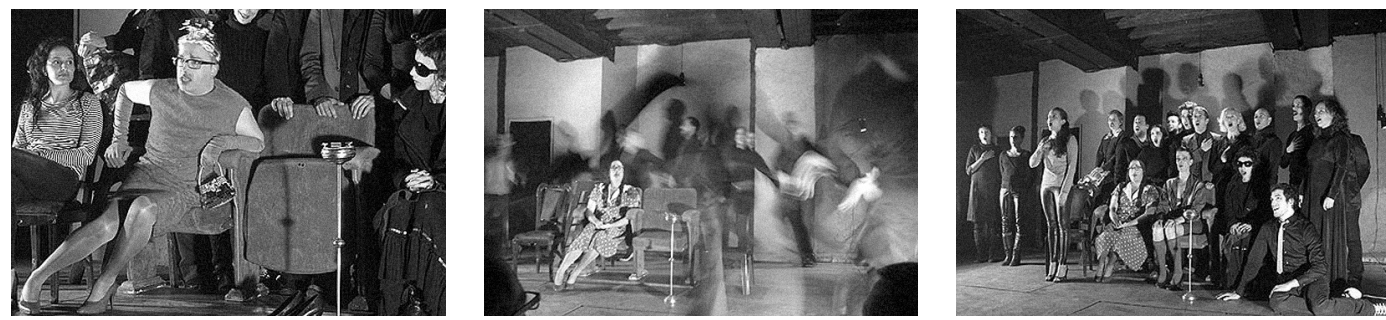

ensaiada, o que lança a sua representação numa vertigem de acasos, improvisações e tensões não só desejadas como necessárias. Deste modo, o texto aproxima-se do registo irrepetivel e único da performance, que a encenação segue e intensifica, suscitando nos actores um estado de hipervigilância e responsabilidade do presente. Uma vez obrigados a seguir as indicações do encenador, os actores, sentados numa fila de poltronas, atrás das quais se erguem os figurantes do quadro, repetem as falas enunciadas, e, numa poderosa adrenalina, o espaço para o imponderável é claramente potenciado, gerando uma dinâmica muito particular no espectáculo.

Destas premissas resulta uma comicidade hilariante, reforçada com momentos de autêntica festa, com pequenas danças a despropósito, que mais não serviam senão para sublinhar o riso e a alegria do fazer, demarcando-se, assim, de toda a embotada e mediana "arte séria". Esta alegria demonstraram-nos esplendidamente os actores: Álvaro Correia revelou-se uma espampanante e ingénua Juanita (versão diva saloia), Luz Câmara um Fidel intempestivo e desmesurado (versão gore), Patrícia Andrade um Che delicado (versão gay), Luísa Brandão, um Raul nobre e melódico (versão farsa), Gonçalo Ferreira de Almeida, um encenador atentíssimo e vertiginoso (versão superstar com écharpe Pierre Cardin). Mas os figurantes não ficaram atrás no ranking do disparate. Miguel Loureiro convidou para o retrato de Juanita a sua família artística e afectiva e não é sem ironia que nomes reconhecidos em diferentes estilos e áreas artísticas, ao lado de outros menos famosos, se deliciaram a participar como figurantes nesta peça: Maria Duarte (Projecto Teatral), Maria João Falcão (evidente para um público televisivo), André Guedes (artista plástico),

Miguel Pereira ou Margarida Mestre (bailarinos e coreógrafos). Em certa medida, este foi, simultaneamente, o retrato da família artística de Miguel Loureiro, que não existe longe dos afectos.

Não obstante as evidentes ressonâncias estéticas entre a proposta de Miguel Loureiro e o ambiente warholiano, este espectáculo não se reduz a uma visita de culto à época; ele actualiza, com a vitalidade da equipa reunida, uma obra perante a qual, propositadamente, se distancia. Por outras palavras, Miguel Loureiro enquadra o texto de Tavel num plano auto-reflexivo, através de duas claras opções: por um lado, introduz uma espécie de prólogo inicial, a cargo da figura do anfitrião (Fabrizio Pazzaglia), que, como Ihe compete, recebe o público e lhe apresenta o espectáculo, terminando com a chamada à cena, pelo nome, os actores e figurantes. É ainda o anfitrião que justifica o cenário, ou melhor, a ausência dele: ele explica o que o público deveria ver, não fora o encenador e cenógrafo, José Capela, terem prescindido da sua materialização, indiferente para o espectáculo. Propondo a ideia de cenário como plano de fiç̧ão e não a sua concretização visual, cria-se uma situação irónica, sublinhada com a oferta aos espectadores de folhetos explicativos do projecto de cenário, que contribui para uma correcta parcimónia do gesto. Por outro lado, Miguel Loureiro coloca-se a si mesmo na meta-posição de encenador interveniente durante a representação, dando indicações práticas aos actores, do seu lugar remoto atrás do público. Ele posiciona-se como um vigia na torre de guarda, ligando os dois planos que pretende fazer coincidir: aponta um olhar órfico para o universo da Factory, que não procura embalsamar no espectáculo, mas convocar para se posicionar face às suas próprias influências, e, ao mesmo tempo, cria um novo olhar, um outro possivel, calibrado com leveza e rigor.

Há ainda um último aspecto a salientar e que diz respeito ao diálogo com a história. Fazendo todo o sentido epidérmico no contexto explosivo da ruptura artística que constituiram os anos 60 em Nova lorque, onde nasce 0 irreprimivel happening e a performance, como se pode compreender a relevância de fazer um texto do teatro do ridículo hoje em Portugal? Creio que a resposta a esta pergunta se prende com dois factores principais. Um deles relaciona-se, obviamente, com o facto de, para um criador culto como Miguel Loureiro, a interpelação de momentos da história do teatro se constituir como um natural itinerário da sua pesquisa. Ao fazê-lo, o encenador desenha para si um território estético na relação com esse passado, em que todos os tempos e todos os códigos se cruzam no mesmo plano, onde todos são tornados contemporâneos. De um outro ponto de vista, este projecto de Miguel Loureiro apresenta claras sintonias com o momento que a própria performance atravessa actualmente em relação às suas origens e aos seus nomes maiores, a nivel internacional. Desde o início do século $X X I$, a performance assiste a um momento de revisitação ou revivalismo com contornos particulares, por vezes, encabeçado pelos próprios artistas, outras vezes, com acções promovidas por instituições no âmbito de exposições ou festivais de carácter retrospectivo. São exemplos Marina Abramović, que refez sete performances seminais dos anos 60 e 70, no Museu Guggenheim (Seven Easy Pieces, 2005); Anna Halprin que, em colaboração com Anne Collod e convidados, recriou uma das suas coreografias mais marcantes e à qual pudemos assistir recentemente na Culturgest (Parades \& Changes, 1965; Parades \& Changes, Replays, 2008); ou André Lepecki que recriou o primeiro happening designado com o tal, 18 Happenings in 6 Parts (1959), de Allan Kaprow, a partir das notas pessoais do autor, no contexto da exposição retrospectiva dedicada ao artista, promovida pela Haus der Kunst de Munique (18 Happenings in 6 Parts - Redoing, 2006). Neste movimento duplo entre a singularidade do percurso de Miguel Loureiro e a sintonia estética internacional, criamse obras como Juanita Castro e tudo leva a crer que, por mais recriações que surjam, não haverá outra como a do Cais do Sodré. 